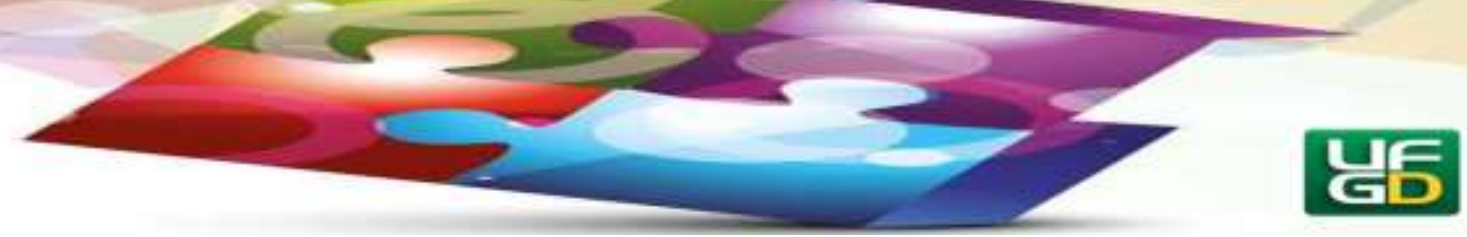

\title{
A CONSTITUIÇÃO DO GRUPO DE ELABORAÇÃO DA BNCC DE ENSINO DE CIÊNCIAS: TRAJETÓRIAS DE SEUS ATORES SOCIAIS E SEUS IMPACTOS NA ELABORAÇÃO DA PROPOSTA
}

\section{THE CONSTITUTION OF THE BNCC SCIENCE TEACHING CORPUS: TRAJECTORIES OF ITS SOCIAL ACTORS AND THEIR IMPACTS ON THE ELABORATION OF THE PROPOSAL}

\author{
Felipe MUNERATTO ${ }^{1}$ \\ Rodolfo Henrique de SOUZA ${ }^{2}$ \\ Matheus IANELLO ${ }^{3}$ \\ Diego Nunes NAVARRO ${ }^{4}$ \\ Graciella WATANABE ${ }^{5}$
}

\section{Resumo}

A produção do texto da Base Nacional Comum Curricular (BNCC) em ciências naturais teve a presença de profissionais da educação que atuaram no ensino superior e constituem o corpus deste documento, isto é, os sujeitos que fizeram parte da escrita desse documento são agentes sociais que produzem práticas contextualizadas pelas suas posições de poder e o que elas representam. Para esse trabalho, pretende-se mapear os agentes que fizeram parte da elaboração da versão final da BNCC, de modo que se possa compreender em que medida as trajetórias históricas e sociais desses atores no campo científico (seja ele como cientista ou aprendiz) e universitário podem trazer elementos de sua prática para os contextos de produção do documento. O uso de análise dos currículos Lattes dará suporte para compreender alguns indícios do impacto da formação desses profissionais para o entendimento de como os diferentes interesses associados aos campos de origem são tratados na elaboração da BNCC.

Palavra-chave: Campo Científico. BNCC. Ensino de Ciências. Trajetórias. 


\section{HORIZONTES - REVISTA DE EDUCACATO}

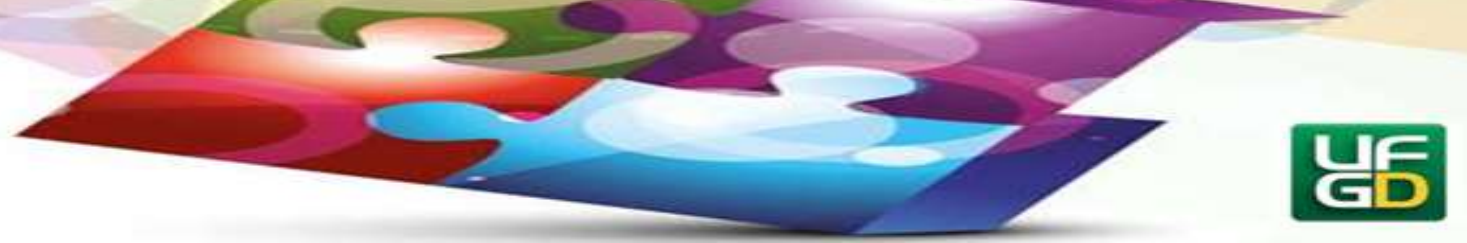

The corpus of production of "CCC" (Common Core Curriculum) text in natural sciences had its constitution professionals in education, either in the scope of action in higher education. However, they are constituted by social agents that produce knowledge contextualized by their positions in the fields of power. For this study it was intend to map some subjects that it possible to understand what extent in historical and social trajectories of these actors in the scientific (be it as a scientist or apprentice) and university fields can bring elements of their practice to the BNCC context of production. The Curriculum Lattes analysis can provide some insight into the impact of these professionals on understanding how the different interests associated with their source fields may be addressed to the BNCC production.

Keywords: Scientific Field. BNCC. Science Teaching. Pathways.

\section{Introdução}

O espaço educacional brasileiro, historicamente, é o lugar marcado por confrontos entre diferentes setores da educação que, particularmente, representam visões concorrentes. Nos últimos anos, esse cenário de disputa sob a ótica empresarial desenvolveu-se e intensificou-se numa busca por políticas e ações neoliberais. Nesse sentido, Laval (2004) já apontava como o destaque ao capital humano útil profissionalmente pode ser perverso uma vez que o discurso neoliberal traz constantemente a prerrogativa de uma escola eficaz, transformando a escola em um espaço empresarial com foco voltado para produção de sujeitos úteis ao mercado.

As disputas profundas e mudanças radicais que estão ocorrendo na educação pública brasileira não podem ser dissociadas da conjuntura política e econômica vividas no país, principalmente no sentido da instauração de novos blocos de poder advindo de rupturas e coalizões entre novos protagonistas políticos.

Leher (2017) aponta que desde 2007 grupos empresariais atuam junto às ações do governo Federal na educação básica, tal qual o Plano de Desenvolvimento da Educação e o Plano Nacional de Educação (2014-2024). Somado a tal desafio, o empresariado difunde sua agenda por meio de coalizões externas ao governo, como o projeto Todos pela Educação, cooptando boa parte do terceiro setor. Nessa perspectiva, o Plano Nacional de Educação trouxe a discussão sobre a construção de uma Base Nacional Comum Curricular (BNCC) e a Reforma do Ensino Médio, tendo suas bases na Lei № 13.415/2017.

A BNCC, que começa a ser formulada ainda no primeiro semestre de 2015, reúne membros de associações científicas representando diversas áreas do conhecimento, o Conselho 


\section{HORIZONTES - REVISTA DE EDUCACATO}

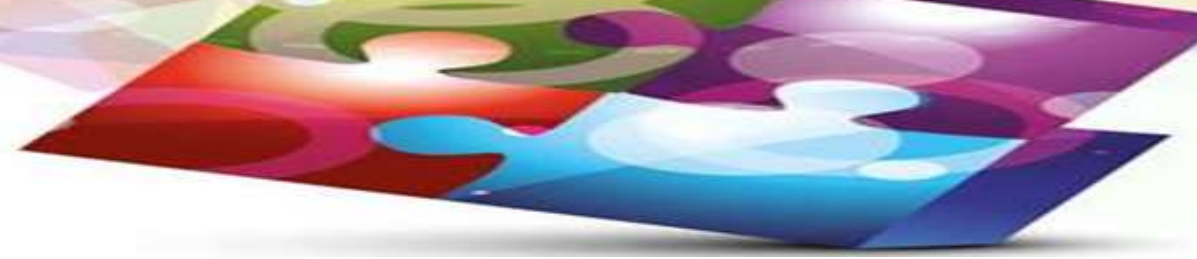

Nacional dos Secretários da Educação (CONSED), a União Nacional dos Dirigentes Municipais da Educação (UNDIME), e representantes do terceiro setor, compostos principalmente pela ONG Movimento pela Base Nacional Comum (MARSIGLIA et al., 2017).

O objetivo principal da BNCC, como consta no documento introdutório, é oferecer subsídios às propostas curriculares, trazendo a preocupação com as especificidades que caracterizam as escolas brasileiras, de tal forma entendida como caráter normativo que define o conjunto orgânico e progressivo de aprendizagens essenciais que todos os alunos devem desenvolver ao longo de suas trajetórias formativas na Educação Básica (BRASIL, 2016).

Silva (2015) argumenta que a Base vai em sentido oposto ao entendimento de que enfrentar as desigualdades passa por respeitar e atentar para a diferença e diversidade de todos os tipos, desde a condição social até diferenças étnico-raciais e de gênero. Dessa forma, a padronização é contrária ao exercício da liberdade e da autonomia, seja escolar, seja dos educadores, seja dos estudantes.

Em consonância, Girotto (2018) aponta que a BNCC não propõe enfrentar as desigualdades educacionais brasileiras, uma vez que entre seus objetivos não explícitos está o reforço dessa desigualdade. Para esse autor, os produtores da BNCC não temem o fracasso da proposta, uma vez que já têm os culpados caso a proposta não seja frutífera: os professores. Assim, reafirmam a lógica de responsabilização unidimensional que marca as políticas educacionais sob o neoliberalismo. Curiosamente, a lógica empresarial é usada como argumento para ser implementada na gestão das unidades escolares (GIROTTO, 2018).

Ao longo da história de construção das teorias de currículo é sabido a existência das diversas perspectivas, como, por exemplo, as de Bobbitt (2004), Dewey (1959), Tyler (1983), Apple (1982, 1986), as quais não são objetos de estudos neste artigo, mas permitem reflexionar e inferir a diversidade de princípios norteadores e os respectivos impactos na sociedade. Com efeito, ainda que haja modificações das concepções sobre currículos conforme os contextos sociais e a finalidade educacional num determinado período de tempo, são intrínsecos e relacionais a ele, a definição de quais conhecimentos devem ser incluídos no currículo, isto é, quais devem ser ensinados na sala de aula. Em concordância com Lopes e Macedo (2011), tal seleção de conhecimentos está em consonância e é consequência da concepção de finalidade da escola, defendendo, assim, determinados conhecimentos em detrimento a outros. Ademais, “ensinar supõe esforços, custos, sacrifícios de toda a natureza. No próprio sentido da palavra, é 


\section{HORIZONTES - REVISTA DE EDUCACATO}

necessário o que se ensina valha a pena" (FORQUIN, 1993) e, portanto, articulando a justificação deste esforço.

Disto, pois, as contribuições de Forquin (1993) numa abordagem sociológica favorece a compreensão de currículo não apenas como um objeto técnico, mas como um artefato cultural e social, e que neste artigo é partilhado. Assim, compreende-se um pertencimento íntimo entre cultura e educação, o que implica que dentre os domínios - o escolar - ocorra a transmissão da herança cultural com entendimento de cultura como um patrimônio intelectual. No entanto, em que perspectiva a narrativa da construção da sociedade humana será abordada?

Com efeito a seleção de conteúdos implica logicamente na exclusão (ou omissão) de um repertório de sentidos, e numa perspectiva mais ampla de determinações sociais e contexto de sua produção. O currículo não é, portanto, um elemento inocente e neutro de transmissão desinteressada do conhecimento social. O currículo implica relações de poder, transmite visões sociais particulares e produz visões do indivíduo e da sociedade (MOREIRA, SILVA; 1994).

Dessa forma, cabe uma reflexão não reducionista de interpretação da BNCC apenas como um documento normativo que está em conformidade com a Lei de Diretrizes e Bases (1996) e o Plano Nacional de Educação (2014), mas que tal documento define o conjunto de aprendizagens que deve ser perpassado ao longo da trajetória do aluno na Educação Básica no território nacional, e, portanto, na inferência da mobilização de conhecimentos reconhecidos e legitimados pelas disputas de poder. Concomitantemente, a BNCC mostra-se relevante porque é dela que emanam os alinhamentos de outras políticas públicas educacionais como as associadas às avaliações e formação de professores, nas três esferas federativas, bem como a oferta de infraestrutura para o desenvolvimento da educação.

Com a participação de diversos setores que não pertencem ao campo educacional, dáse a entender uma propensão fortemente relacionada à interesses políticos e demandas de grupos econômicos ao invés da melhoria da qualidade do ensino ou o bem-estar social e comum da população. Um debate que foge, portanto, do meio científico, representados por pesquisadores da área, ainda que se reconheça a relevância de cada agente social na construção de um documento nacional.

Partindo desse conjunto de reflexões, pretende-se investigar no presente trabalho, como as condições de produção de um documento curricular como a BNCC se constitui pelas 


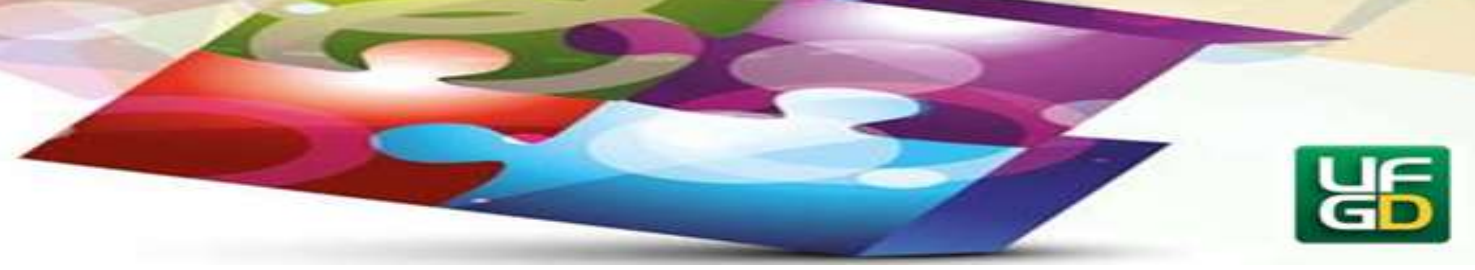

diferentes percepções do sentido de educar, assim como, seus produtores representam interesses e objetivos fortemente atrelados aos seus campos sociais de atuação.

Para tanto, a pergunta de pesquisa pretende compreender: Como se constitui o grupo social que produziu a BNCC de Ciências da Natureza de que modo se podem reconhecer as produções e posições provindos de seus campos sociais para a produção de um currículo nacional?

Partindo dessa questão de pesquisa, serão abordados:

1. A ideia de campo e fronteira como conceitos para ajudar na compreensão dos sujeitos que produziram a BNCC em Ensino de Ciências;

2. Elaboração de estudos sobre os perfis e relações acadêmicas que podem dar indícios dos espaços sociais e os interesses por eles constituídos;

3. Construção de grafos das relações que se estabelecem entre conhecimentos científicos e seus agentes sociais.

\section{O campo científico, a fronteira e seus usos na constituição do corpus analisado}

A educação brasileira perpassa diferentes instâncias de atuação que vão desde conselhos federais até o "chão da sala de aula". Na didática francesa, intelectuais buscaram entender como se constituiu ou, ainda, se constitui essa complexa relação que perpassa elementos da didática das ciências (ASTOLFI, DEVELAY, 1994), os processos de produção do saber (CHEVALLARD, 1991) e a profissionalização docente (TARDIF, 2012). A dificuldade de compreender a educação em conjunto com seus processos não é tema trivial e não pode ser tratado como mera ligação entre diferentes espaços e objetivos, mas como um emaranhado social, cultural, político e epistêmico, que muda constantemente conforme as forças sociais e geracionais adentram ao debate.

Coutinho (2005) faz-nos pensar como se dão as distintas formas de nos tornarmos adultos, na perspectiva da constituição da psique, que, levando aos processos de interação social, provocam a retomada de uma aproximação às perdas dos grandes ideais através do reconhecimento dos grupos sociais juvenis. Essa dimensão geracional não pode ser ignorada, pois reflete, todo tempo, na formação de novas ideias, novos grupos, novas formas de ver o mundo fora e dentro da escola. Contudo, algo permanece sob o ponto da formação acadêmica. 


\section{HORIZONTES - REVISTA DE EDUCACATO}

Essa dimensão, que se poderia reconhecer como uma trajetória histórica, rememora as ideias e ideais que cada aluno leva após aproximar-se de um grupo de intelectuais "com e contra eles", como aponta o sociólogo Pierre Bourdieu (2004a).

Assim, ao olhar para as trajetórias históricas dos profissionais e para a constituição do grupo que se formou para elaboração da BNCC serão elaborados diferentes olhares possíveis para compreender os interesses e objetivos que se associam às suas trajetórias históricas.

Em geral, existem diferentes formas de compreender esse universo cultural e social da educação. O conceito de campo reconhece esse lugar como espaço social que possui um conjunto de regras bem estabelecidas e que refletem em um jogo social com interesses e disputas, portanto, sendo capaz de congregar sujeitos em prol de um objetivo comum, assim como um lugar que possui, fundamentalmente, uma historicidade, que evoca a dimensão de lutas que vão definindo sua existência ao longo de um processo complexo de autonomia (CATANI, 2017). Para as pesquisas bourdieusianas a ideia de campo representa uma forma de dar suporte para olhar a complexidade desse espaço social.

O campo científico possui, assim, temática crucial, pois ela dispõe sobre um conceito "caro" para os estudos das ciências: a ideia de "comunidade científica". Quando cunhada por Merton como um espaço social agregador dos interesses das ciências, sejam tanto pelos atores sociais quanto práticas da ciência, a ideia de comunidade de certo modo entoou um olhar social em que as disputas políticas camuflam-se ao debate das teorias ou problemas científicos em embate.

Ainda que não se pretenda, aqui, debater sobre o conceito em si, cabe ressaltar que a ideia central permanece, seja na perspectiva dos objetivos que fazem com que o campo social seja um espaço de lutas, como na necessidade de pensar em sua historicidade.

Desse modo, a ideia de estudo da constituição do grupo cujos representantes são de diferentes campos sociais pode dar suporte para compreender como a constituição da produção da Base Nacional Comum Curricular se apresenta como lugar de disputa e de defesa das tradições científicas e culturais dos grupos dos quais esses sujeitos proveem.

A ideia de mobilizar tal aparato reforça a visão de que a produção de conhecimentos perpassa diferentes artefatos culturais (ideais, preconceitos, demandas) que conduzem a um tipo de pensamento que busca emergir-se do novo a partir da constituição do diferente. A ideia de fronteira na perspectiva sociológica, portanto, será aqui debatida como esse instrumento de 


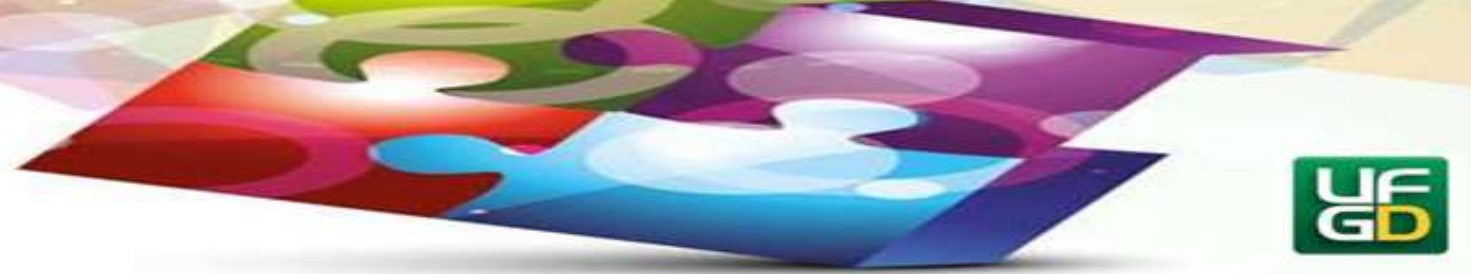

produção de outros saberes que na aproximação entre diferentes campos sociais, elaboram perspectivas simbólicas do que "se deve" ensinar enquanto conhecimento curricular.

A ideia de fronteira aqui tratada reflete o lugar social onde os diferentes campos sociais se aproximam. Nesse espaço encontram-se disputas simbólicas, delimitações de interesses e lutas por legitimações (ÀGUAS, 2013) provenientes de diferentes espaços sociais em disputa. São esses espaços sociais que definem as lutas desiguais e que caracterizam o que se constitui como o novo, seja em termos de reconhecimentos do que é importante ser pensado como conhecimento como o que é importante de ser negado como conhecimento.

Ao trabalhar tal perspectiva, portanto, se reconhece que a fronteira existirá sempre no conflito ainda que não, necessariamente, seja um instrumento reflexivo pessimista, mas pode ser compreendido como um lugar na qual diversidade e a pluralidade convive para pensar novas formas de pensar a si e os outros (MARTINS, 1996).

No que se refere ao presente trabalho, a ideia de fronteira torna-se um aparato reflexivo interessante para compreendermos qual a "bagagem cultural científica" que os participantes da produção da BNCC trazem, de modo que se possa, posteriormente, compreender as posições desses sujeitos nos contextos de seus campos de origem, lugar onde atuam como intelectuais, sejam pesquisadores em ensino e agentes da escola, como profissionais de áreas correlatas.

Tal análise, assim, pode trazer luz aos questionamentos como a ausência de determinados saberes no documento da base e a distribuição desigual de conhecimentos científicos em diferentes etapas da formação na educação básica. Ainda que não se possa reconhecer que esse tipo de construção das distribuições dos aparatos culturais seja suficiente para dar suporte ao problema levantado em sua totalidade, ele se mostra importante meio de iniciar a construção do desvelamento desse mundo social.

\section{Metodologia de Pesquisa}

Este trabalho se constitui como um tipo de análise documental, com ênfase em material público, em particular, com o objetivo de constituir dados com credibilidade científica, de modo a extraí-los próximos de uma realidade social analisada (SILVERMAN, 2009). Optou-se por trabalhar exclusivamente com documentos oficias disponibilizados em portarias e editais, assim como os próprios currículos apresentados via instituições governamentais. 


\section{HORIZONTES - REVISTA DE EDUCACATO}

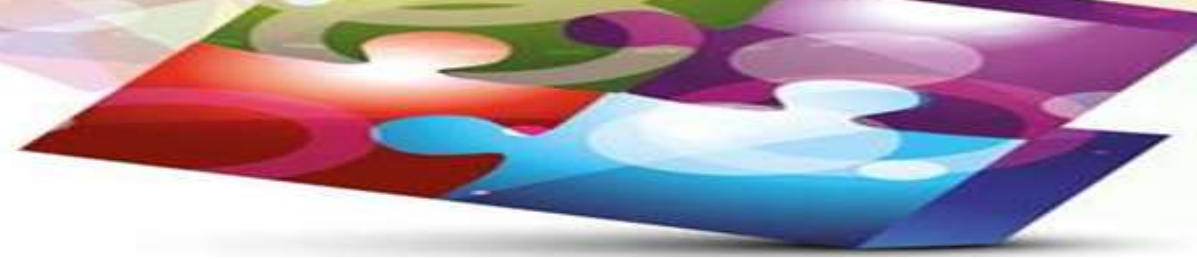

Diante disto, a análise aqui proposta é voltada à área das Ciências Naturais e, a partir da versão final da BNCC disponibilizada no próprio site do $\mathrm{MEC}^{6}$, investigou-se os redatores e a comissão de especialistas que se enquadrassem nesse aspecto, sendo assim, redatores e especialistas que contribuíram para a elaboração da BNCC na área das Ciências Naturais. Porém, vale salientar que a dificuldade associada a uma análise temporal da BNCC está relacionada com a maneira como ela foi estruturada ao longo do tempo.

A BNCC, que foi elaborada em três momentos distintos, apresenta características inerentes a esses momentos, constituindo os seguintes documentos: a primeira versão; a segunda versão e a versão final. A primeira versão não apresenta redatores; a segunda versão especifica quem foram os redatores e a respectiva área de contribuição; e a versão final do documento apresenta os redatores, porém não especifica por área de atuação.

Desta forma, a escolha por analisar a versão final se dá, principalmente, porque tal documento compreende as mudanças realizadas e identificam tanto os Redatores como a Comissão de Especialistas, detalhando quais sujeitos fizeram parte da segunda versão e da versão final, no mesmo documento. Também, cabe apontar que as terminologias e classificações se alteram entre a segunda versão e a versão final, de modo que na primeira versão a Comissão de Especialistas foi dividida por disciplinas tal como Português, Inglês, Matemática, etc. Na segunda versão em diante, a Comissão passou a ser separada em coordenação, redatores, leitores críticos e demais classificações.

A partir da análise produzida ao longo da investigação, notou-se que os Redatores e a Comissão de Especialistas foram compostos por Professores Universitários, Professores de Escola Básica, indicações associadas ao Conselho Nacional dos Secretários da Educação (CONSED) e à União Nacional dos Dirigentes Municipais de Educação (UNDIME). Mas, optou-se, para a análise, dar foco aos Professores Universitários, pelos seguintes motivos: Professores Universitários são sujeitos responsáveis pela produção acadêmica do país, portanto, são pesquisadores - sujeitos que representam a academia - esperava-se que esses sujeitos possuíssem currículo Lattes cadastrados.

Dado o foco adotado, entendemos que os dados obtidos são de fator determinante para discutir a confiabilidade dos mesmos, visto que, justamente, referem-se à produção acadêmica

\footnotetext{
${ }^{6}$ Disponível em: http://basenacionalcomum.mec.gov.br/images/BNCC_EI_EF_110518_versaofinal_site.pdf
} 


\section{HORIZONTES - REVISTA DE EDUCAÇÃO}

e intelectual dos pesquisados. Além disto, dificuldades em delimitar uma amostra foram encontradas, pois alguns sujeitos não possuíam o currículo cadastrado na plataforma, enquanto outros não tinham informações relevantes para o propósito da pesquisa. Isto é, a disponibilização dos dados dos pesquisados está delimitado pelo interesse destes sujeitos a integrar à plataforma.

Porém, esta circunstância não prejudica a proposta desta investigação, já que se pretende analisar alguns redatores, sobretudo, aqueles que têm informações atualizadas no Lattes. Ademais, como há o interesse em analisar o capital cientifico de tais sujeitos, que é do tipo simbólico, fundado no conhecimento e reconhecimento legitimado pelos outros agentes (BOURDIEU, 2004b), a plataforma do currículo Lattes torna-se relevante, pois está nela a representação nacional dos pesquisadores brasileiros, que por sua abrangência e confiabilidade, tornou-se objeto de análise, por exemplo, em algumas etapas para financiamentos. O currículo Lattes é, portanto, um dos instrumentos de maior impacto para dar crédito científico a sujeitos.

Como critério de exclusão e inclusão, utilizou-se, não só ter sido colaborador na escrita do documento da BNCC, mas também ter o currículo cadastrado na plataforma Lattes, obtendo, portanto, vinte e seis sujeitos. Esses sujeitos foram organizados pela a área de formação, sendo estas: Física, Química, Biologia, Ciências/Geologia.

Neste grupo de vinte e seis sujeitos, nenhum participante trabalhou na elaboração da parte de "Ciências da Natureza e suas Tecnologias" ao longo das versões produzidas do documento, ou seja, há interrupções dessas trajetórias na produção da base entre a segunda versão e a versão final, objeto de nossa análise.

Para tratar das formações acadêmicas foram analisados os currículos Lattes destes participantes por meio de análises de categorias como suas graduações e pós-graduações (Strictu Sensu), produção acadêmica e orientações. No critério de produção acadêmica foram considerados os artigos produzidos nos últimos dez anos e presente em revistas com QUALIS CAPES A1/A2 ou B1/B2 nas áreas de Ensino e/ou Educação. O intuito de considerar as produções mais recentes, utilizando da qualis-periódicos, busca-se trazer, de certo modo, o reconhecimento associado pelos seus pares e a influência dessa produção nos seus campos de origem. Os dados foram coletados e tabulados para posterior elaboração de grafos de relações entre os agentes do campo. Os grafos elaborados foram feitos no software open source Gephy® 


\section{HORIZONTES - REVISTA DE EDUCACATO}

e-ISSN: 2318-1540

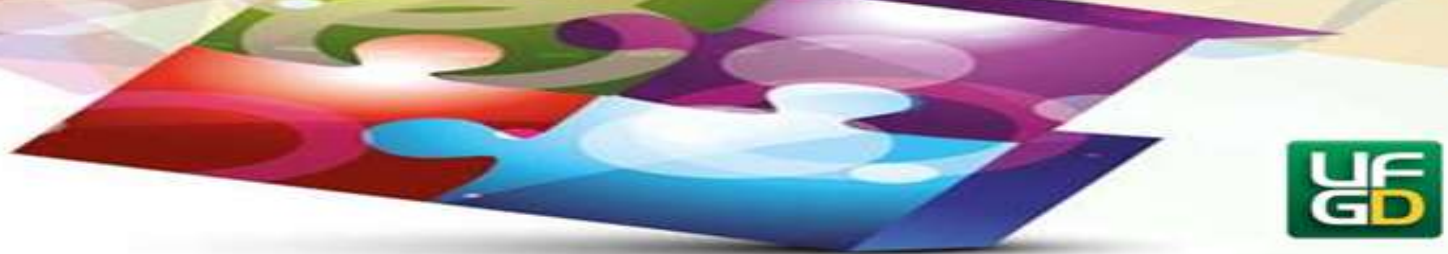

e possuem como objetivo compreender algumas relações estabelecidas entre produtores e instituições, assim como, na construção dos laços sociais entre esses sujeitos.

\section{Resultados e Discussão}

Bourdieu (2011) discute as relações entre ciência, cultura e reproduções sociais, explicitando uma intrincada explicação sociológica da dominação social, desvelando as regras do campo científico ao demonstrar interesses, conflitos, crises e relações de força existentes na academia. O sociólogo francês mostra a existência de hierarquia social entre as faculdades e instituições de pesquisa (BOURDIEU, 2011). Ao olhar o campo científico brasileiro, devemos levar em conta que se trata de um espaço de disputas onde os agentes sociais desse campo estão inseridos em estruturas e em posições que dependem de seu capital. O capital científico pode, portanto, adquirir duas perspectivas: um poder temporal ou político institucionalizado que está ligado à ocupação de posições importantes nas instituições de ensino superior e de pesquisa; e o capital científico puro, de prestígio e que repousa do reconhecimento dos pares cientistas bem como das instituições. Os dois tipos de capitais têm processos de acumulação diferentes, contudo, o capital científico puro é aquele adquirido, principalmente, pela produção de publicações (BOURDIEU, 2004a). Ainda que não se pretenda aqui tratar os capitais científicos ou fazer uma análise detalhada dos capitais na estrutura do campo universitário e científico brasileiro, optou-se conforme literatura, reconhecer o papel das publicações como elemento importante para análise das posições dos sujeitos em seus campos de origem. Cabe ressaltar que nesse sentido, o espaço escolar torna-se suprimido, ainda que haja outros elementos aqui não estudados que poderiam ser trazidos para comparação.

Assim, dada à perspectiva da mudança de gestão política pós-impeachment, que impactou diretamente na produção acadêmica, visto que os participantes da segunda versão foram, em sua maioria, destituídos e substituídos por outro grupo, fez-se relevante analisar como a distribuição das publicações foi alterada de uma versão para outra. Para isso, os artigos foram somados e divididos pelo número de colaboradores, pois assim a terceira versão, por ter um menor número de escolhidos, não sairia diretamente prejudicada na análise. Será atribuído a este fato o nome de impacto relativo (IR). Os resultados estão apresentados no Quadro 1. 


\section{HORIZONTES - REVISTA DE EDUCAÇÃO}

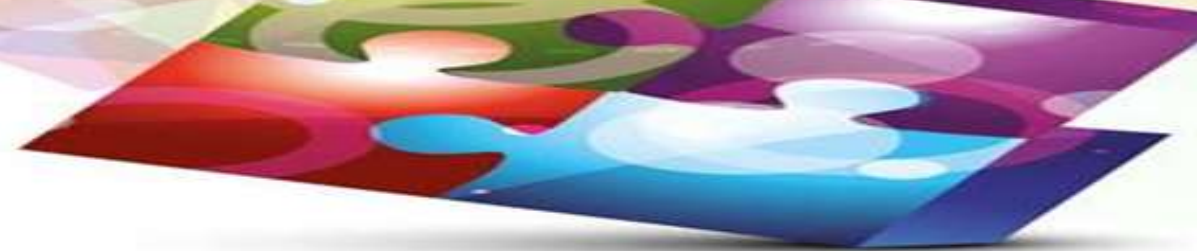

Quadro 1 - Resultados da distribuição de capital científico puro

\begin{tabular}{|c|c|c|c|c|c|c|c|c|c|}
\hline & $\begin{array}{l}\text { Quantidade } \\
\text { total de } \\
\text { artigos } \\
\text { publicados }\end{array}$ & $\begin{array}{c}\text { Quantidade } \\
\text { de artigos } \\
2010-2019\end{array}$ & $\begin{array}{c}\text { Quantidade } \\
\text { de artigos } \\
\text { em revistas } \\
\text { A1-A2 } \\
\text { (Ensino) }\end{array}$ & $\begin{array}{c}\text { Quantidade } \\
\text { de artigos } \\
\text { em revistas } \\
\text { A1-A2 } \\
\text { (Educação) }\end{array}$ & $\begin{array}{c}\text { Quantidade } \\
\text { de artigos } \\
\text { em revistas } \\
\text { B1-B2 } \\
\text { (Ensino) }\end{array}$ & $\begin{array}{c}\text { Quantidade } \\
\text { de artigos } \\
\text { em revistas } \\
\text { B1-B2 } \\
\text { (Educação) }\end{array}$ & $\begin{array}{c}\text { Quantidade } \\
\text { de } \\
\text { supervisões } \\
\text { em Pós-Doc } \\
\text { defendidos }\end{array}$ & $\begin{array}{c}\text { Quantidade } \\
\text { de alunos } \\
\text { Doutorados } \\
\text { defendidos }\end{array}$ & $\begin{array}{c}\text { Quantidad } \\
\text { e de alunos } \\
\text { Mestrado } \\
\text { defendidos }\end{array}$ \\
\hline $2^{\mathrm{a}}$ Versão & 450 & 231 & 94 & 77 & 88 & 70 & 3 & 76 & 245 \\
\hline $3^{\mathrm{a}}$ Versão & 36 & 8 & 3 & 3 & 4 & 1 & 1 & 3 & 8 \\
\hline $\begin{array}{c}\text { IR } 2^{\mathrm{a}} \\
\text { Versão }\end{array}$ & 23,68 & 12,16 & 4,95 & 4,05 & 4,63 & 3,68 & 0,16 & 4 & 12,89 \\
\hline $\begin{array}{c}\text { IR } 3^{\mathrm{a}} \\
\text { Versão }\end{array}$ & 5,14 & 1,14 & 0,43 & 0,43 & 0,57 & 0,14 & 0,14 & 0,43 & 1,14 \\
\hline
\end{tabular}

Fonte: Elaboração dos autores, 2019.

É possível perceber a queda do impacto relativo de uma versão para outra. Consequentemente há uma queda, também, das publicações dos autores, resultando em um menor reconhecimento de seus pares e menos inserção em termos de publicação no campo em questão. Os resultados podem dar indícios de que os autores da terceira versão estão menos inseridos no campo científico educacional, sendo mais suscetíveis aos interesses políticos e econômicos externos a ele. Tal fato decorre, homologamente à concepção da autonomia do campo, isto é, a capacidade de refratar demandas ou pressões externas a ele, assim como caracteriza-se o campo científico. O contrário também é válido, isto é, estaria expresso problemas externos, inclusive os políticos, num campo heterônomo (BOURDIEU, 2004a). Essa dimensão aparece também posteriormente quando se analisa as orientações e instituições dos quais provém, sendo, em sua maioria, ex-alunos de docentes reconhecidos no campo educacional.

Ainda que haja algumas distinções entre o grupo que se constitui na segunda versão e na versão final da BNCC, pode-se reconhecer que elas são parte de uma construção mais ativa do processo de elaboração da proposta, ou seja, que se reconhece certa credulidade que ambos grupos tiveram papel relativamente importante na produção da base mesmo que o grupo final tenha sido reconhecido como os autores da proposta final. Nesse sentido, para se entender como o grupo e seus interesses foram constituídos, optamos por tratar os campos da Biologia, Física, Química e Ciências/Geologia separadamente, ainda que este último seja representado apenas por um agente. 


\section{HORIZONTES - REVISTA DE EDUCACATO}

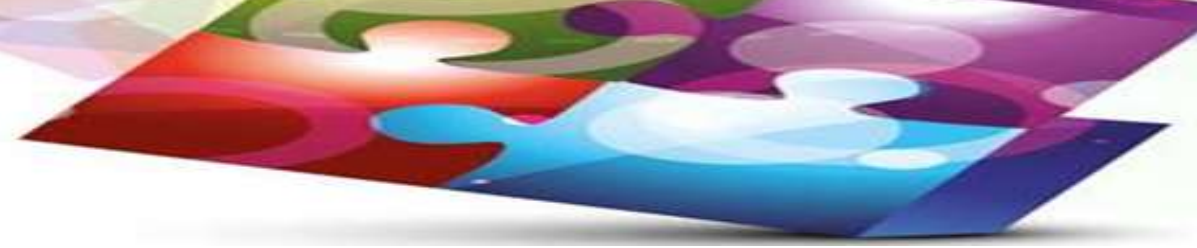

Inicialmente, observa-se que para cada um dos quatro grupos há um único pós-doutor, os quais realizaram seu pós-doutoramento em universidades estrangeira, salvo o da Física, que realizou pela Universidade de Campinas. Essa representação da hierarquia universitária demonstra, a priori, como se deu a constituição das posições e interesses desses sujeitos na elaboração da base. Em outras palavras, cabe questionar em que medida a hierarquia universitária teve impacto na elaboração do documento, em especial, reconhecendo que a transmutação dos capitais pode ser ainda valorativa nas interações sociais na fronteira (WATANABE, 2015).

Ao detalharmos as formações dos sujeitos, entre os grupos, percebe-se algumas relações distintas como, por exemplo refere a hierarquia de titulações acadêmica (graduação, mestrado, doutorado, pós-doc). Na Biologia há um total de 10 agentes, sendo dois agentes apenas com graduação, dois com mestrado, cinco com doutorado e um com pós-doutorado; na Física há 8 indivíduos, sendo dois com mestrado, cinco com doutorado e um pós-doutor; na Química, grupo constituído por 7, há um com graduação, três com mestrado, dois com doutorado e um pós-doutorado; e como já mencionado, o agente representando o grupo Ciências/Geologia, com pós-doc em Educação.

As formações são distintas, contudo, aos que apresentam doutorado, são, em sua maioria, pesquisadores oriundos da Universidade de São Paulo $(n=8)$ e Unicamp $(n=2)$. Universidades como UnB, UFSM, UFBA e UFMT aparecem nessas formações. Ao analisar esses dados, alguns nomes de orientadores chamam a atenção, pois refletem o perfil dos pesquisadores e suas heranças acadêmicas como forma de pensamento. Alguns desses participantes da construção da base são oriundos das pós-graduações cujos orientadores são docentes que anteriormente estiverem envolvidos com os Parâmetros Curriculares Nacionais (PCN e PCN+). Também, encontram-se nomes de orientadores com forte vínculo com as propostas e políticas educativas nas instituições federais (CAPES, MEC, CNPq). Ainda que não haja qualquer tipo de subordinação intelectual, tais heranças acabam por trazer elementos da formação desses profissionais, que inevitavelmente, também influenciam suas formas de compreender a produção de saberes e propostas educativas.

Sob esse viés, ressalta-se que os sujeitos participantes da última versão, apesar de estarem inseridos no campo científico educacional, não estão no pináculo, em termos de publicações, da influência científica, mesmo apresentando outras produções relevantes na área. 


\section{HORIZONTES - REVISTA DE EDUCACATO}

e-ISSN: $2318-1540$

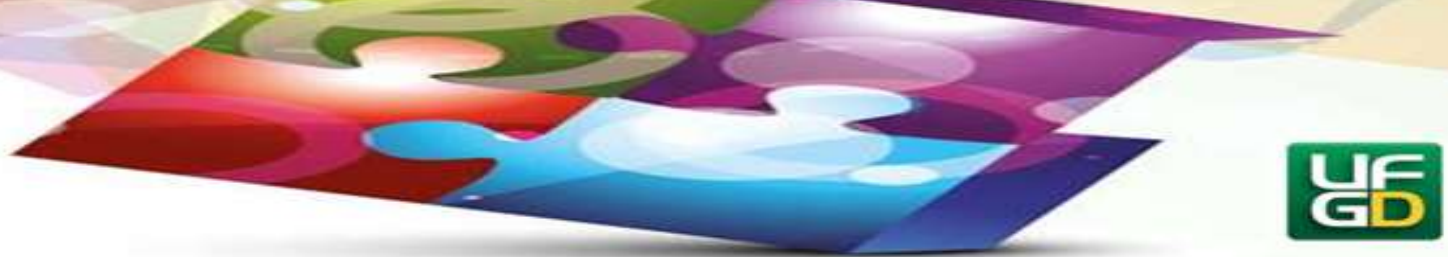

Contudo, como já mencionado, é interessante observar de quais universidades esses sujeitos são provenientes. Na figura 01 temos um grafo que mostra a relação de universidades por autores no sentido em que quanto maior a participação de uma universidade na trajetória formativa acadêmica de dado autor, isto é, graduação, mestrado, doutorado, pós-doutorado, maior o nome dela no grafo.

Figura 01 - Grafo das Universidades nas quais os Autores se Formaram.

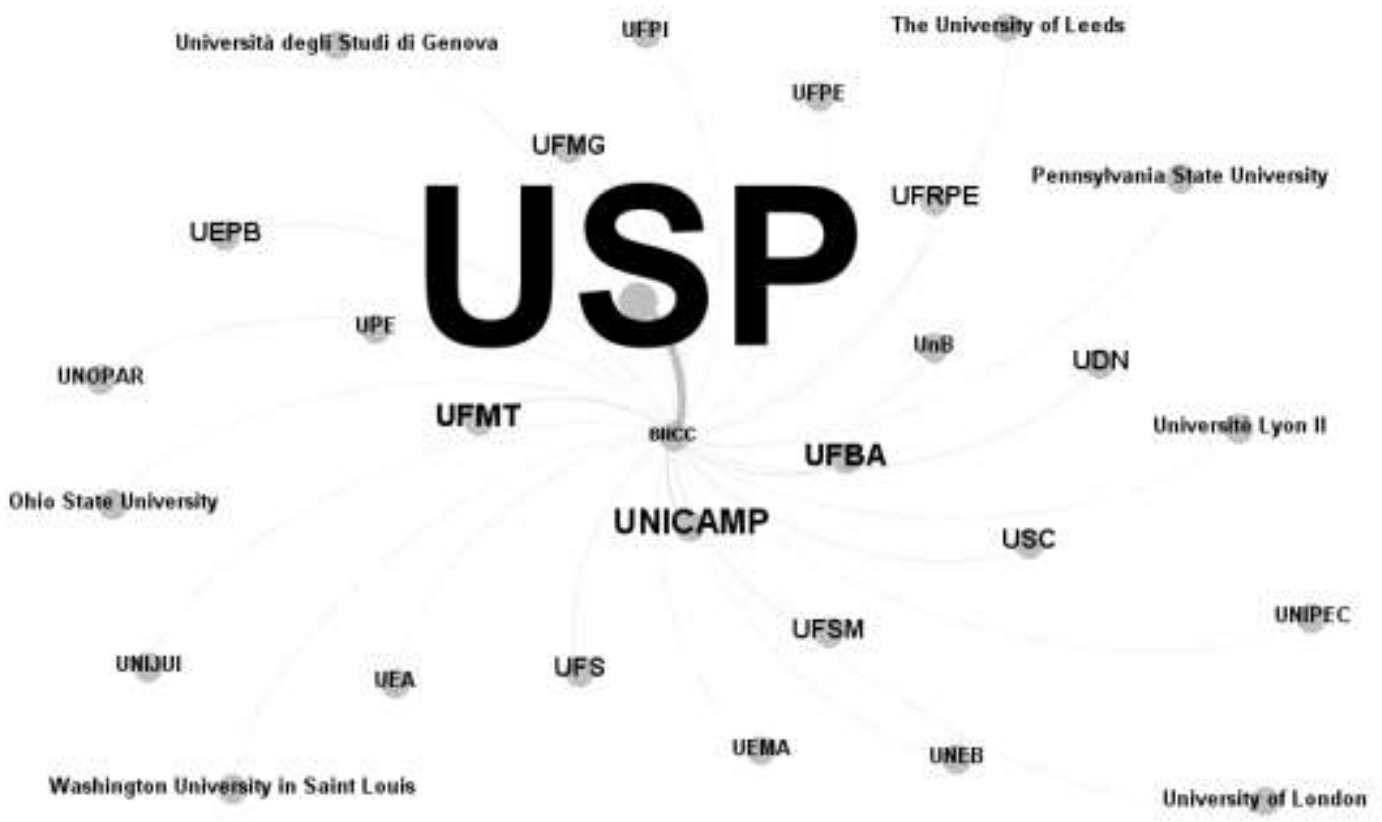

Fonte: Elaboração dos autores, 2019.

Percebemos grande relevância da Universidade de São Paulo (USP) na trajetória dos autores da BNCC, possivelmente por seu capital simbólico no campo acadêmico e por estar entre as melhores universidades do país quanto ao ensino, pesquisa e citações, por exemplo, além da representatividade seu volume de alunos (THE WORLD UNIVERSITY RANKINGS, 2016; 2019). O interessante de tal grafo, no entanto, é perceber como outras instituições como a Universidade Federal da Bahia, Universidade Federal do Mato Grosso, Universidade de Minas Gerais e Unicamp também figuram nas trajetórias formativas desses sujeitos. Outro dado interessante é a respeito da presença de universidades estrangeiras nessas trajetórias, mesmo que singularmente aparentam pouca participação, a quantidade de diferentes instituições do exterior chama a atenção. 


\section{HORIZONTES - REVISTA DE EDUCAÇÃO}

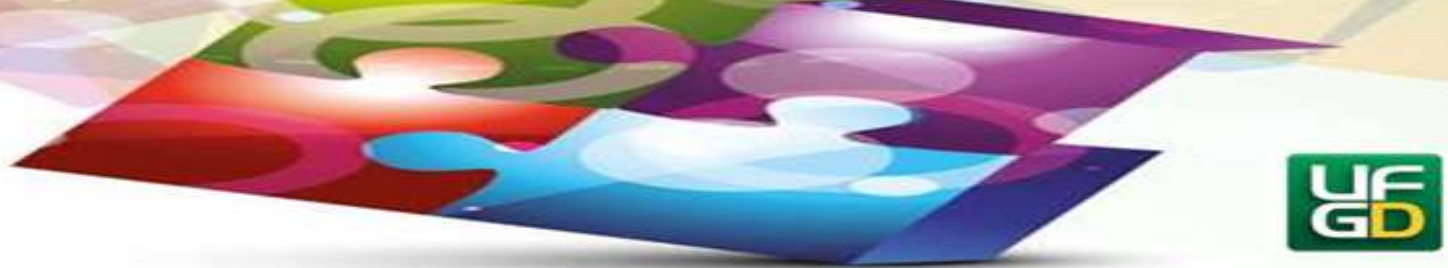

Continuando nossa análise da relação entre conhecimento científico e esses agentes sociais que participaram da escrita da BNCC, na figura 02 temos um grafo que representa: no ponto, cada pesquisado (exceto o ponto central preto, que representa a BNCC); na cor, a área de formação inicial do pesquisado (graduação); e na aresta, a intensidade de orientações. Isto é, quanto mais espessa a aresta, maior a representatividade do pesquisado ter sido envolvido com orientações de mestrado e/ou doutorado. Ressalta-se que o comprimento da aresta, não apresenta significações.

Entendemos a orientação como um fator importante na constituição de capital científico uma vez que é possível que o fruto dessas orientações, além de formação científica, são as publicações de artigos e resumos apresentados em congressos. Notamos na figura 02 que os sujeitos da área da física atuaram em mais orientações que os da química e respectivamente mais do que os da biologia.

Figura 02 - Grafo Áreas por Capital Científico (Orientação).

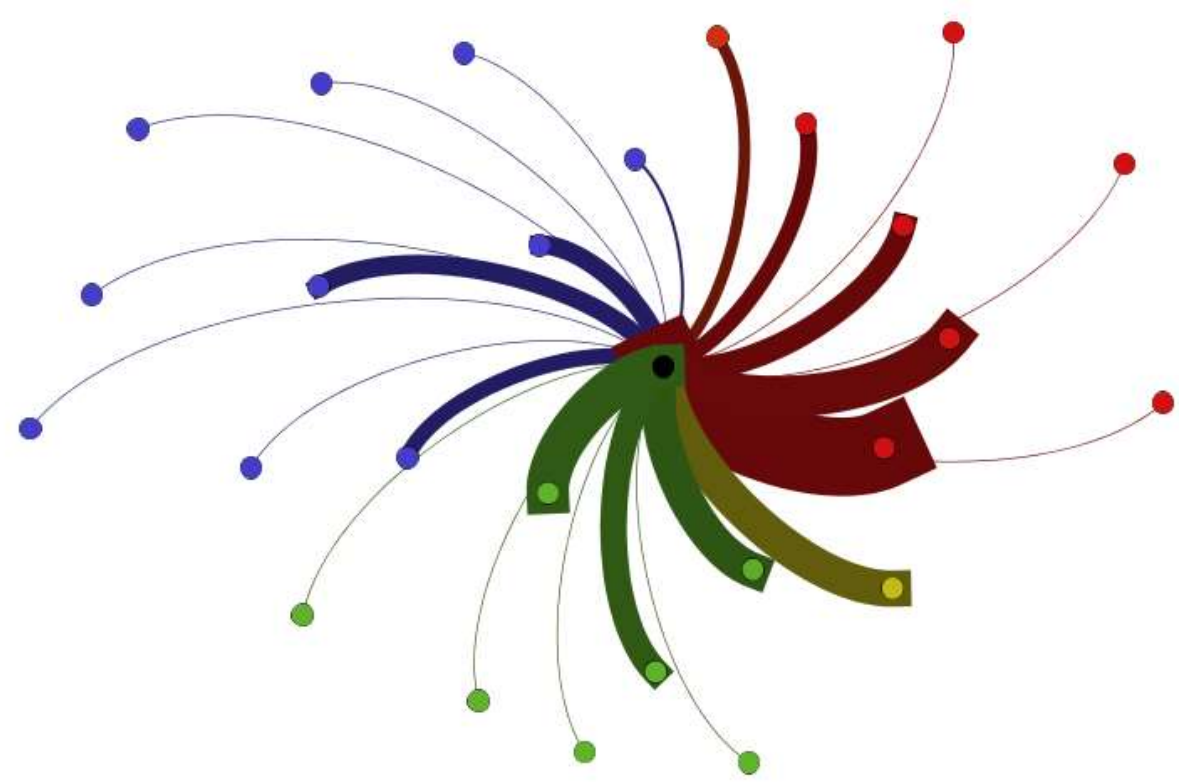

Azul: Biologia; Verde: Química; Vermelho: Física; Amarelo: Ciências/Geologia.

Fonte: Elaboração dos autores, 2019.

Sob a mesma perspectiva analisamos a genealogia dos autores associado a seu capital científico na perspectiva de orientação. Na figura 03 vemos um grafo onde os nós representam 


\section{HORIZONTES - REVISTA DE EDUCAÇÃO}

e-ISSN: $2318-1540$

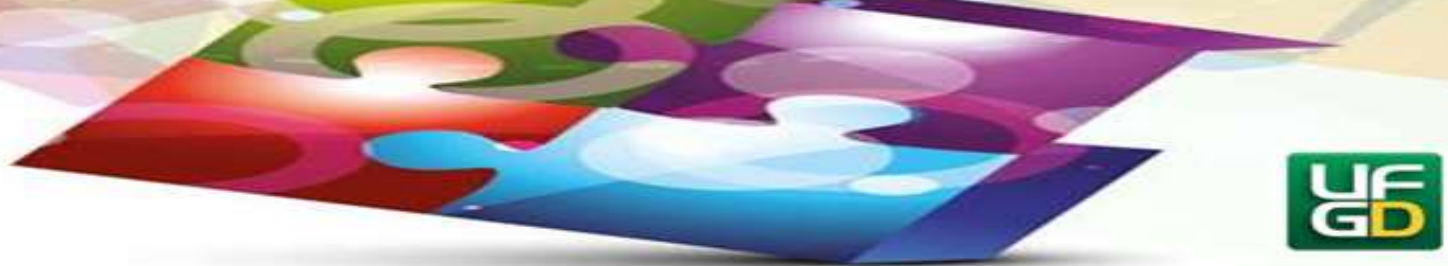

os autores e quanto maior o nó maior sua relação com os outros nós e a grossura da aresta significa quantidade de orientações de mestrado e doutorado realizadas. Notamos aqui, portanto, a genealogia em comum de grupos de autores e, principalmente, a relação de não autores da BNCC (nós pretos) com os demais sujeitos, destacando que esses grupos iniciam sua rede de articulação durante sua trajetória formativa.

Figura 03 - Grafo da Genealogia e Capital Científico (Orientação).

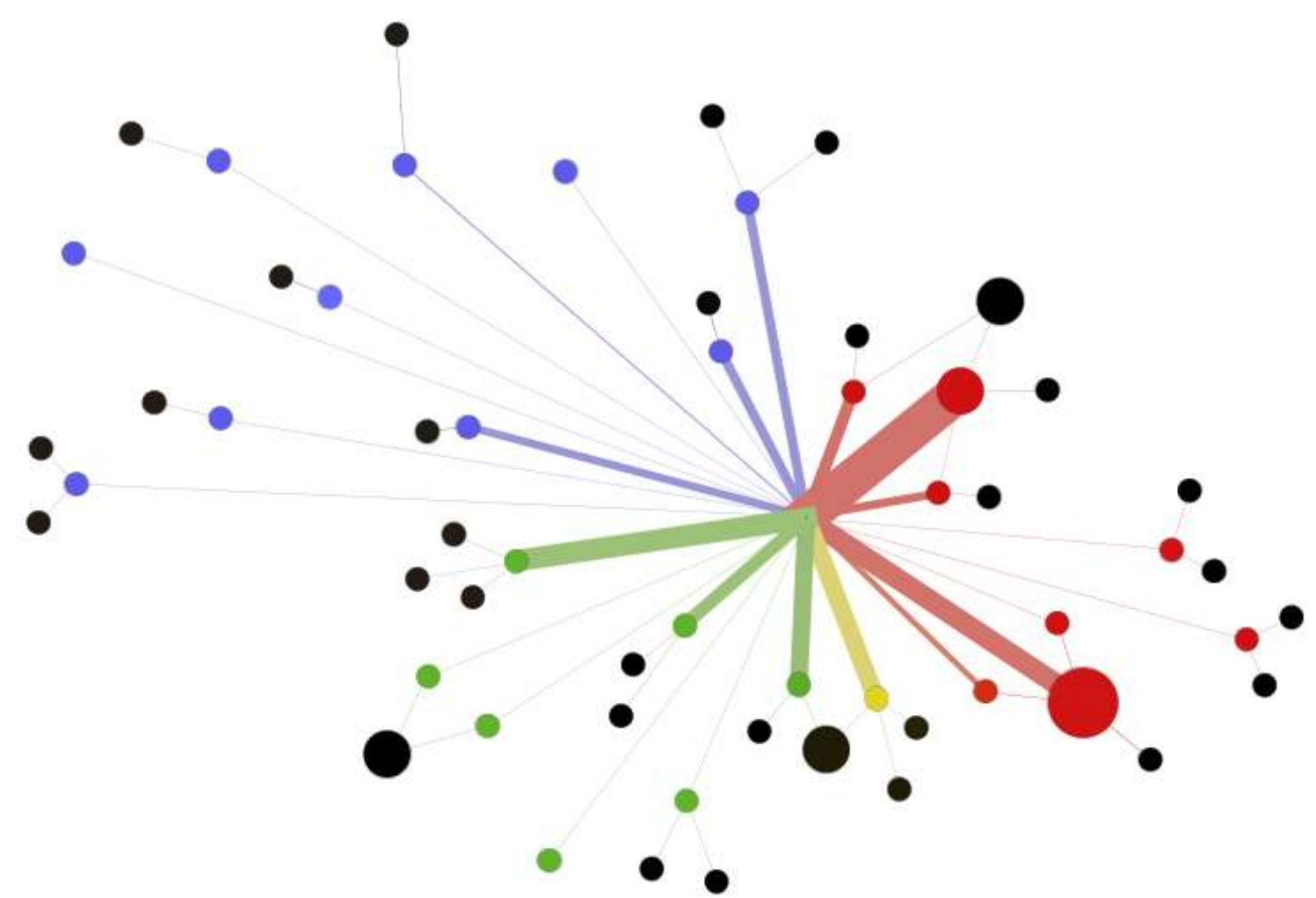

Azul: Biologia; Verde: Química; Vermelho: Física; Amarelo: Ciências/Geologia; Preto: Orientadores e Não Autores da BNCC.

Fonte: Elaboração dos autores, 2019.

Outro fator determinante para análise das posições desses sujeitos no espaço social do ensino de ciências é constituído pelas produções de artigos e formações que provém de seus grupos de pesquisa e pós-graduações em que atuam. Nesse sentido, podemos reconhecer que o tempo de atuação pode influenciar de modo substancial as quantidades de publicações e orientações desses agentes sociais. Em especial, optou-se por não fazer tal distinção, mas reconhecendo suas dimensões e inserções no campo da pesquisa conforme a temporalidade em 


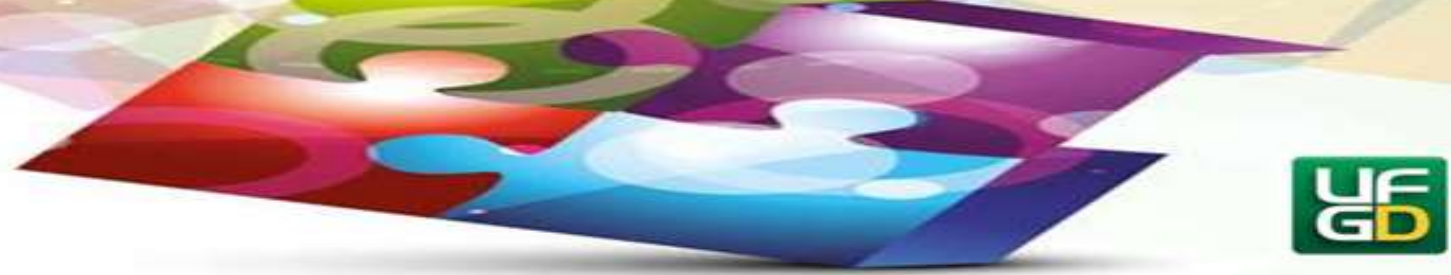

que atuam. Observa-se, também, que há indicativos de elaboradores que não atuam na pesquisa, portanto, o que justifica essas ausências. Para esses profissionais, pode-se reconhecer que sua atuação se encontra na educação básica. No quadro 2 temos a sumarização da produção acadêmica dos vinte e seis sujeitos.

Quadro 02 - Capital Científico Puro por Produção Acadêmica em Educação e Ensino e Orientações Realizadas.

\begin{tabular}{|c|c|c|c|c|c|c|c|c|}
\hline \multicolumn{9}{|c|}{ Produção Acadêmica e orientações } \\
\hline Área & $\begin{array}{c}\text { Quantidade } \\
\text { total de } \\
\text { artigos } \\
\text { publicados }\end{array}$ & $\begin{array}{c}\text { Quantidade } \\
\text { de artigos em } \\
\text { revistas A1- } \\
\text { A2 } \\
\text { (Ensino) }\end{array}$ & $\begin{array}{l}\text { Quantidade de } \\
\text { artigos em } \\
\text { revista } \\
\text { A1-A2 } \\
\text { (Educação) }\end{array}$ & $\begin{array}{c}\text { Quantidade } \\
\text { de artigos em } \\
\text { revistas B1- } \\
\text { B2 (Ensino) }\end{array}$ & $\begin{array}{c}\text { Quantidad } \\
\text { e de artigos } \\
\text { em revistas } \\
\text { B1-B2 } \\
\text { (Educação) }\end{array}$ & $\begin{array}{c}\text { Quantidad } \\
\text { e de } \\
\text { supervisões } \\
\text { em Pós- } \\
\text { Doc } \\
\text { defendidos }\end{array}$ & $\begin{array}{c}\text { Quantidad } \\
\text { e de alunos } \\
\text { Doutorado } \\
\text { s } \\
\text { defendidos }\end{array}$ & $\begin{array}{c}\text { Quantidad } \\
\text { e de alunos } \\
\text { Mestrado } \\
\text { defendidos }\end{array}$ \\
\hline BIOLOGIA & 50 & 10 & 8 & 21 & 13 & 1 & 2 & 14 \\
\hline BIOLOGIA & 37 & 15 & 14 & 10 & 11 & - & 6 & 11 \\
\hline BIOLOGIA & 23 & 7 & 3 & 9 & 6 & - & 1 & 13 \\
\hline BIOLOGIA & 21 & - & - & - & - & - & 1 & 1 \\
\hline BIOLOGIA & 1 & - & - & - & - & - & - & - \\
\hline BIOLOGIA & 1 & - & - & - & - & - & - & - \\
\hline BIOLOGIA & 1 & - & - & - & - & - & - & - \\
\hline BIOLOGIA & - & - & - & - & - & - & - & - \\
\hline BIOLOGIA & - & - & - & - & - & - & - & - \\
\hline BIOLOGIA & - & - & - & - & - & - & - & - \\
\hline FÍSICA & 79 & 12 & 9 & 15 & 11 & - & 8 & 65 \\
\hline FÍSICA & 23 & 5 & 1 & 4 & 8 & - & 5 & 17 \\
\hline FISICA & 16 & 1 & - & 1 & 2 & - & - & 15 \\
\hline FISICA & 11 & 3 & 3 & 3 & 1 & 1 & 2 & 7 \\
\hline FISICA & 6 & 2 & 2 & - & - & - & 8 & 30 \\
\hline FÍSICA & 1 & - & - & 1 & - & - & - & - \\
\hline FÍSICA & - & - & - & - & - & - & - & - \\
\hline FÍSICA & - & - & - & - & - & - & - & - \\
\hline QUÍMICA & 89 & 19 & 22 & 5 & 5 & - & 23 & 16 \\
\hline QUÍMICA & 41 & 7 & 6 & 11 & 4 & - & 8 & 24 \\
\hline QUÍMICA & 20 & - & - & 5 & 2 & - & 2 & 22 \\
\hline QUÍMICA & 1 & - & - & - & - & - & - & - \\
\hline QUÍMICA & - & - & - & - & - & - & - & - \\
\hline
\end{tabular}


QUÍMICA

QUÍMICA

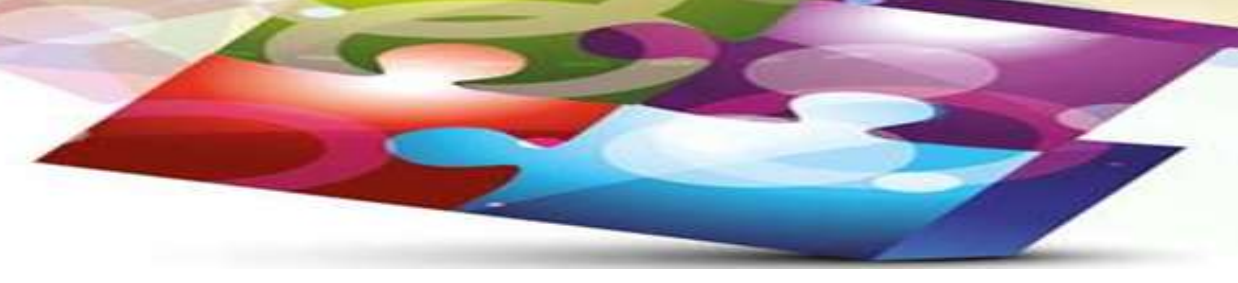

Fonte: Elaboração dos autores, 2019.

O quadro 2 traz informações a respeito da distribuição do capital científico pelas áreas de conhecimento, relacionando com desigualdade científica e a herança acadêmica das áreas. As áreas da Química e Física apresentam um grande nível de desigualdade em produção acadêmica, visto que, em Química, por exemplo, há um sujeito com muita produção (89 artigos), já o segundo apresenta apenas 41 artigos, além de diversos com pouco ou nenhuma produção. Na Física observamos um fenômeno parecido, já que o sujeito com a maior produção está com 79 artigos publicados e o segundo de maior produção com 23 artigos e, de novo, muitos sujeitos com poucas ou nenhuma publicação.

Em contrapartida, ao olhar a produção dos sujeitos relacionados à Biologia percebemos uma maior distribuição de produção, tornando a área mais homogênea e, portanto, menos desigual no que se refere à produção acadêmica. É interessante olhar, também, a relação proposta nas figuras 02 e 03 . Observamos, novamente, uma grande dependência da relação orientador-orientado nas áreas de Química e Física, dado a grande concentração de orientações, enquanto na Biologia essa relação é pulverizada em diversos sujeitos, reforçando a proposição da desigualdade científica existente na Física e na Química.

\section{Considerações Finais}

Esse trabalho é apenas o início de estudos que objetivam desvelar o jogo social associado à escrita de um documento curricular nacional. Para tanto, a partir do levantamento dos autores da BNCC, iniciou-se um trabalho que busca fomentar o debate da participação dos agentes oriundos do campo científico e a sua produção na área de Ciências da Natureza e Tecnologia, bem como nas áreas de pesquisa e atuação na Educação e no Ensino.

Desse modo, pretendeu-se reconhecer como a formação dos autores e suas trajetórias acadêmicas, assim como, suas produções intelectuais, podem indicar alguns aspectos da hierarquia acadêmica e seu impacto na constituição da BNCC. Destaca-se que a trajetória formativa acadêmica dos analisados, representam, simbolicamente, uma formação majoritariamente proveniente da Universidade de São Paulo. Não obstante, observa-se também a presença de universidades internacionais. Questiona-se, assim, em que medida sujeitos em posições de poder, seja do ponto de vista da formação nas pós-graduações, em instituições 


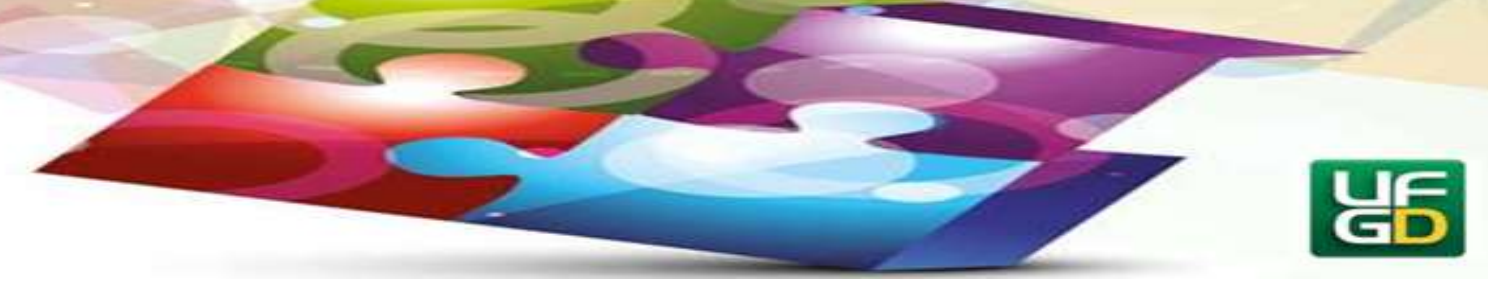

reconhecidas nacional e internacionalmente, podem influenciar os modos como se constituem a ideia do "ensinar ciência" ou "saberes das ciências" que serão privilegiados em detrimento de outros em um currículo.

Tal reflexão é relevante, pois se soma a tal debate a importância das intervenções externas na consulta pública e os critérios estabelecidos para aceitação ou negativa das proposições à escrita do texto. A BNCC é um documento que impactará em toda educação básica nacional, tal proporção torna a sua escrita e participação um jogo de interesses não somente educacionais como políticos, haja vista a diferença de produções da segunda para a terceira versão, demonstrando a distinção da participação de pesquisadores da área da Educação e do Ensino. Nesta direção, os resultados do Impacto Relativo (IR) da segunda para a terceira versão (Quadro 1) ilustram quantitativamente a queda expressiva de todos os indicadores analisados, como por exemplo, quantidade de artigos publicados e de alunos de mestrado defendidos. Depreende-se, portanto, que de forma geral, a terceira versão da BNCC foi constituída por agentes de baixo capital cientifico puro se comparado à segunda versão.

Cabe ressaltar que ainda é necessário analisar de modo substancial a posição dos sujeitos da escola básica que participaram da BNCC. Contudo, o desafio imposto está na falta de dados públicos que possam dar subsídios para fazer tal construção dos dados. Todavia, algumas reflexões podem ser retiradas desse trabalho.

Conforme apontado, o papel dos pesquisadores em posições de destaque no campo acadêmico refletem a importância dada a alguns conteúdos em detrimento de outros. Em especial, destacamos a presença de menor desigualdade científica na área de Biologia, demonstrada por uma maior pulverização de produção científica, como também de relações acadêmicas, evidenciando menor dependência orientador-orientado e, talvez, uma maior pluralidade de concepções educacionais e científicas, impactando na elaboração da BNCC.

Em contrapartida, é interessante evidenciar que à luz da formação dos grupos de áreas de conhecimento, a Física foi a que apresentou uma constituição mais cerrada em si se comparada à Química ou Biologia, por exemplo. Isto é, seus pares apresentam relações acadêmicas fortes, no tocante orientando-orientador, conforme ilustra a figura 3. Essa forte relação pode influir de forma a perpetuar determinadas concepções científicas, herdadas pelos orientadores e, portanto, demonstrando uma, talvez, menor pluralidade. 


\section{HORIZONTES - REVISTA DE EDUCACATO}

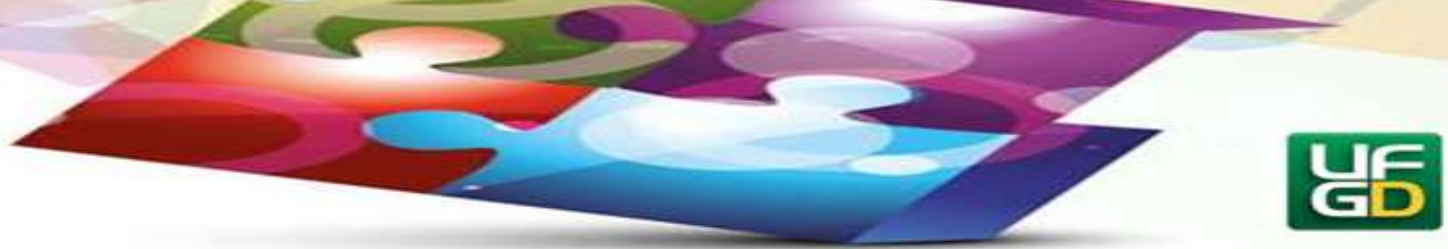

Em suma, o trabalho traz considerações que precisam ser mais bem detalhadas e pensadas, mas refletem, de modo geral, que o desafio da análise da constituição do grupo de produção da BNCC, associada ao ensino de ciências naturais, pode indicar caminhos importantes para compreender o conjunto de interesses e as posições de poder que estão constituindo os conhecimentos privilegiados e negligenciados no documento.

\section{Referências Bibliográficas}

ÁGUAS, Carla Ladeira Pimentel. A tripla face da fronteira: reflexões sobre o dinamismo das relações fronteiriças a partir de três modelos de análise. Fórum Sociológico, v. 23, n. 23, p. 112, 2013.

APPLE, Michael Whitman. Educação e poder. Porto Alegre: Artes Médicas, 1989.

APPLE, Michael Whitman. Ideologia e currículo. São Paulo: Brasiliense, 1982.

ASTOLFI, Jean-Pierre; DEVELAY, Michel. A didática das ciências. Campinas: Papirus, 1994.

BOURDIEU, Pierre. Os usos sociais da ciência. Por uma sociologia clínica do campo científico. São Paulo: Unesp, 2004a.

BOURDIEU, Pierre. Homo Academicus. Santa Catarina: Ufsc, 2011.

BOURDIEU, Pierre. Para uma Sociologia da Ciência. Lisboa: Edições 70, 2004b.

BOBBITT, John Franklin. O currículo. Lisboa: Didática, 2004

BRASIL, Ministério da Educação Gabinete do Ministro. Portaria N 592, de 17 de Junho de 2015. Disponívelem:

<http://www.editoramagister.com/legis_26906831_PORTARIA_N_592_DE_17_

DE. aspx> . Acesso em: 10 Nov. 2019.

BRASIL. Ministério da Educação. Base Nacional Comum Curricular: Educação é a base. Brasília: MEC, 2018. Disponível em: <http://basenacionalcomum.mec.gov.br/>. Acesso em: 13 Set. 2019.

CATANI, Afrânio Mendes. Campo universitário. In: CATANI, Afrânio Mendes;

NOGUEIRA, Maria Alice; HEY, Ana Paula; MEDEIROS, Cristina Carta Cardoso (Orgs.)

Vocabulário Bourdieu. Belo Horizonte: Autêntica, 2017.

COUTINHO, Luciana Gageiro. A adolescência na contemporaneidade: ideal cultural ou sintoma social. Revista da Psicanálise, ano XVII, n. 181, p. 16-23, 2005.

CHEVALLARD, Yves. La transposición didáctica: del saber sabio al saber enseñado. Buenos Aires: Aique, 1991.

DEWEY, John. Vida e Educação. São Paulo: Nacional, 1959. 


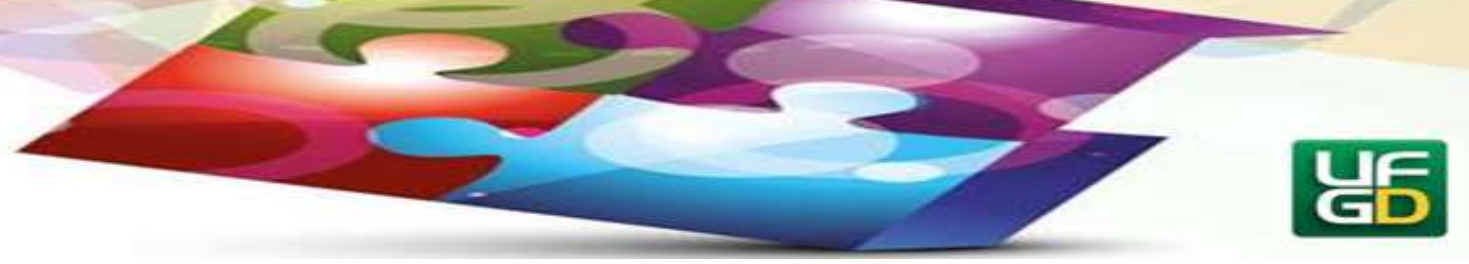

FORQUIN, Jean-Claude. Escola e cultura: as bases sociais e epistemológicas do conhecimento escolar. Porto Alegre: Artes Médicas, 1993.

GIROTTO, Eduardo Donizete. Entre o abstracionismo pedagógico e os territórios de luta: a base nacional comum curricular e a defesa da escola pública. Horizontes v. 36, n. 1, p. 16-30, jan./abr. 2018.

LAVAL, Christian. A Escola não é uma empresa: o neo-liberalismo em ataque ao ensino público. Editora Planta, Londrina. 2004.

LEHER, Roberto; VITTORIA, Paolo; MOTTA, Vânia. Educação e mercantilização em meio a tormenta político-econômica do Brasil, Germinal: Marxismo e Educação em Debate, Salvador, v. 9, n. 1, p. 14-17, abr. 2017.

LOPES, A. C; MACEDO, E. Teorias de currículo. São Paulo: Cortez, 2011.

MARSIGLIA, Ana Carolina Galvão; PINA, Leonardo Docena; MACHADO, Vinícius de Oliveira; LIMA, Marcelo. A Base Nacional Comum Curricular: Um novo episódio de esvaziamento da escola no Brasil. Germinal: Marxismo e Educação em Debate, Salvador, v.9, n.1, p.107-121, abr. 2017.

MARTINS, José de Souza. O tempo da fronteira. Retorno à controvérsia sobre o tempo histórico da frente de expansão e da frente pioneira. Tempo Social, v. 8, n. 1, p. 25-70, 1996.

MOREIRA, Antônio Flávio; SILVA, Tomaz Tadeu. Sociologia e teoria crítica do currículo: uma introdução. In: MOREIRA, Antônio Flávio; SILVA, Tomaz Tadeu. (Orgs.). Currículo, cultura e sociedade. São Paulo: Cortez, p. 7-31, 1994.

SILVA, Monica Ribeiro da. Currículo, ensino médio e BNCC: Um cenário de disputas. Revista Retratos da Escola, Brasília, v.9, n.17, p. 367-379, 2015.

SILVERMANN, David. Interpretação de dados qualitativos. Porto Alegre: Armed, 2009.

TARDIF, Maurice. Saberes docentes e formação profissional. Rio de Janeiro: Vozes, 2012.

THE WORLD UNIVERSITY RANKINGS. The Times Higher Education World University Rankings 2016. Disponível em: <https://www.timeshighereducation.com/times-highereducation-las-10-universidades-de-mayor-prestigio-en-latinoamerica-reveladas-por>

THE WORLD UNIVERSITY RANKINGS. The Times Higher Education World University Rankings 2019. Disponível em: <https://www.timeshighereducation.com/world-universityrankings/2019/world-ranking\#!/page/0/length/25/sort_by/rank/sort_order/asc/cols/stats>

TYLER, Ralph. Princípios básicos de currículos e ensino. 7. ed. Rio de Janeiro: Globo, 1983.

WATANABE, Graciella. A divulgação científica produzida por cientistas: contribuições para o capital cultural. Tese (Doutorado) - Instituto de Física - Faculdade de Educação, Universidade de São Paulo, 2015.

Enviado: 09/06/2020

Aceito: $23 / 06 / 2020$ 